\title{
Focal Congenital Anomalies of the Retinal Pigment Epithelium
}

\author{
J. D. M. GASS \\ Miami, Florida, USA
}

\begin{abstract}
Summary
The terms, 'hamartoma', 'choristoma', 'phacoma' (mother-spot), and 'naevus', are used to describe benign developmental tumours or placoid lesions. Stedman's Medical Dictionary defines a hamartoma as: 'A focal malformation that resembles a neoplasm grossly and even microscopically, but results from faulty development in an organ; it is composed of an abnormal mixture of tissue elements, or an abnormal proportion of a single element, normally present in that site, which develop and grow at virtually the same rate as normal components, and are not likely to result in compression of the adjacent tissue (in contrast to neoplastic tissue).' 1 A choristoma is defined as 'a mass formed by maldevelopment of tissue of a type not normally found at that site.' Phacoma is defined as, 'a hamartoma found in phacomatosis,' a group of hereditary diseases characterised by hamartomas of multiple tissues. A naevus is a, 'birthmark; a circumscribed malformation of the skin, especially if coloured by hyperpigmentation or increased vascularity; it may be predominantly epidermal, adnexal, melanocytic, vascular, or mesodermal, or a localised overgrowth of melanin-forming cells arising in the skin early in life.' Ophthalmologists have adopted the term to refer to developmental melanocytic lesions of the uveal tract, but heretofore have not used it to describe developmental melanocytic, glial, or vascular lesions of the retina.

The purpose of this report is to summarise the author's observations and concepts concerning focal lesions that probably are developmental tumours and placoid lesions composed of either entirely or in part retinal pigment epithelium (RPE). Two of the lesions are tumefactions and may properly be termed 'hamartomas' (Table I). Four of the lesions are placoid and might better be described as naevi. Two are composed of hypertrophied RPE cells engorged with melanin granules, one is presumed to be hypertrophied RPE cells filled with a white pigment of unknown nature and one is composed of RPE cells containing no pigment. Three are widely recognised, three others are not.
\end{abstract}

Classification and Definitions

I. Retinal Pigment Epithelial Hamartoma (RPEH).

These tumours that might also be referred to as congenital pigment epithelial adenomas or primary pigment epithelial hyperplasia are focal, nodular, jet black lesions that usually appear to involve the full thickness of the retina and to spill onto the inner retinal surface in an umbrella fashion (Figs 1,2 and 3). ${ }^{2}$ They typically are one-half to one disc diameter in size. They frequently occur in the

From the Department of Ophthalmology, Bascom Palmer Eye Institute, University of Miami School of Medicine, Miami, Florida, USA.

This investigation was supported in part by Public Health Service Research Grant EY02549, Department of Health and Human Services, National Institutes of Health, National Eye Institute, Bethesda, Maryland; and in part by Research to Prevent Blindness, Inc, New York City.

Correspondence to Bascom Palmer Eye Institute, PO Box 016880, Miami, Florida 33131 USA (Dr Gass). 
Table I Classification of focal developmental anomalies of the retinal pigment epithelium

I. Retinal Pigment Epithelial Hamartoma (congenital retinal pigment epithelial adenoma; primary retinal pigment epithelial hyperplasia)

II. Combined Retinal Pigment Epithelial and Retinal Hamartoma
A. Papillary Type
B. Peripheral Type

III. Melanotic Naevi of the Retinal Pigment Epithelium (congenital hypertrophy of the retinal pigment epithelium)
A. Solitary
B. Grouped

IV. Albinotic and Amelanotic Naevi of the Retinal Pigment Epithelium (congenital albinotic and amelanotic spots of the retinal pigment epithelium)
A. Solitary
B. Grouped

macular area, and are unassociated with changes in the surrounding sensory retina, RPE, and choroid, or with exudation and haemorrhage.

\section{Combined Retinal Pigment Epithelial and Retinal Hamartoma (CRPE-RH)}

These sessile, pigmented, dysplastic tumours that involve the sensory retina and vitreoretinal interface, as well as the RPE, most frequently affect the posterior fundus. Variations in their morphology, as well as in their clinical presentation are related to their location.

A. Papillary type. Those that involve the optic nerve head are typically discovered in young adults who present because of metamorphopsia caused by retinal striae radiating into the macula from the edge of a slightly elevated mottled pigmented tumour with ill-defined borders involving the optic nerve head and juxtapapillary retina (Fig. 4). ${ }^{3-6}$ Clusters of fine capillaries interspersed among the pigmented tissue give the tumour a mossy or filagree appearance. A thin crinkled semi-translucent membrane partly covers the tumour surface. Irregular atrophic changes in the RPE may surround the edge of the tumour. Fluorescein angiography demonstrates the capillary angiomatous nature of this tumour. Visual loss is occasionally caused by intraretinal and subretinal exudation derived either from the tumour or subretinal neovascularisation, or from vitre-

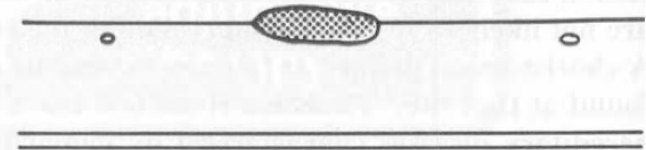

A

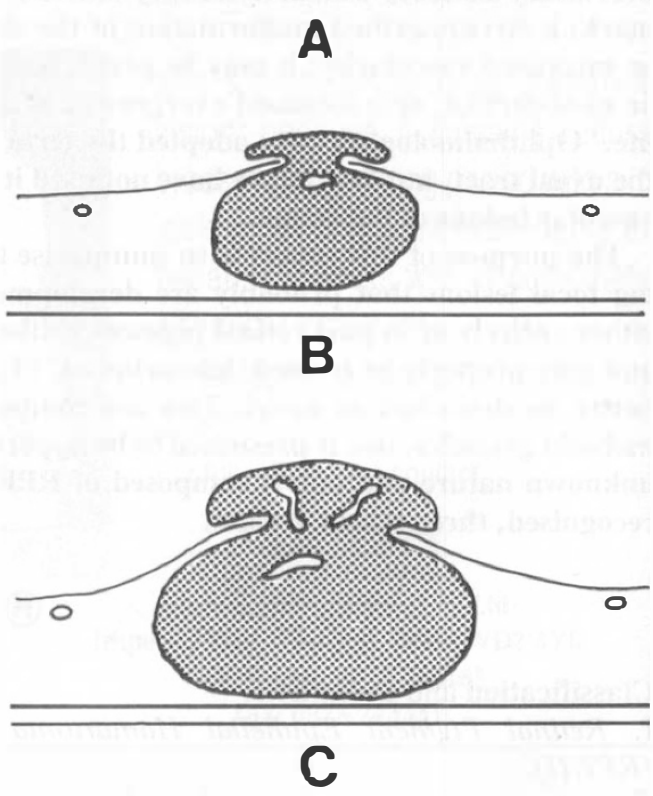

Fig. 1. Diagram intraretinal retinal pigment epithelial hamartoma. A. Superficial. B. Preretinal extension. $C$. Preretinal extension with superficial vacularisation.

ous haemorrhage derived from new vessels on the tumour surface..$^{7,8,9}$

These dysplastic tumours of the optic nerve head and surrounding retina consist of 

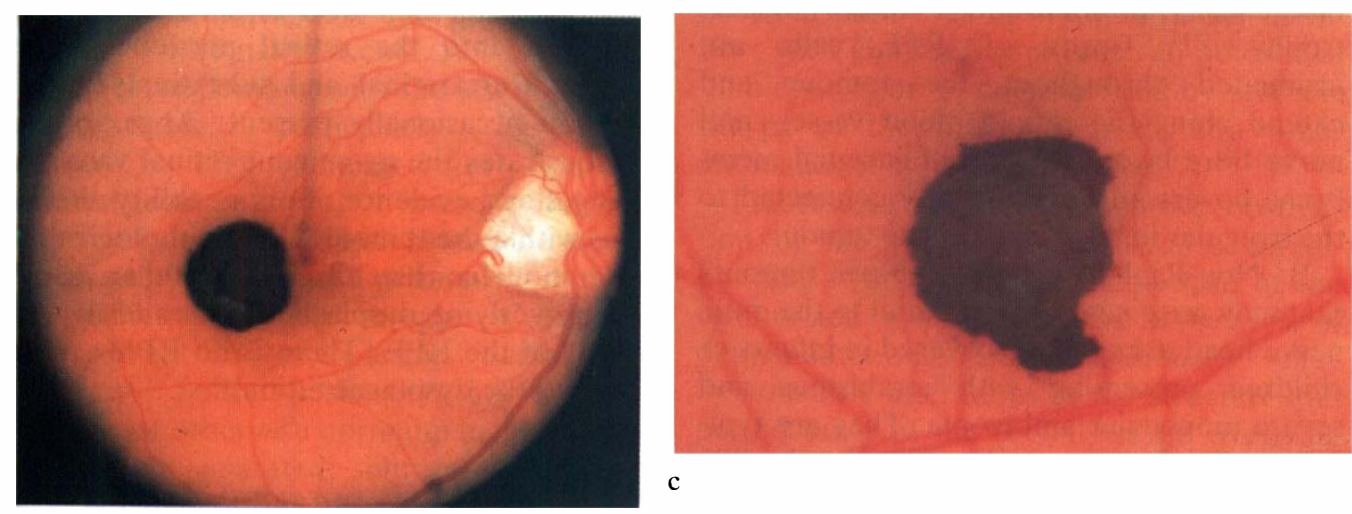

a
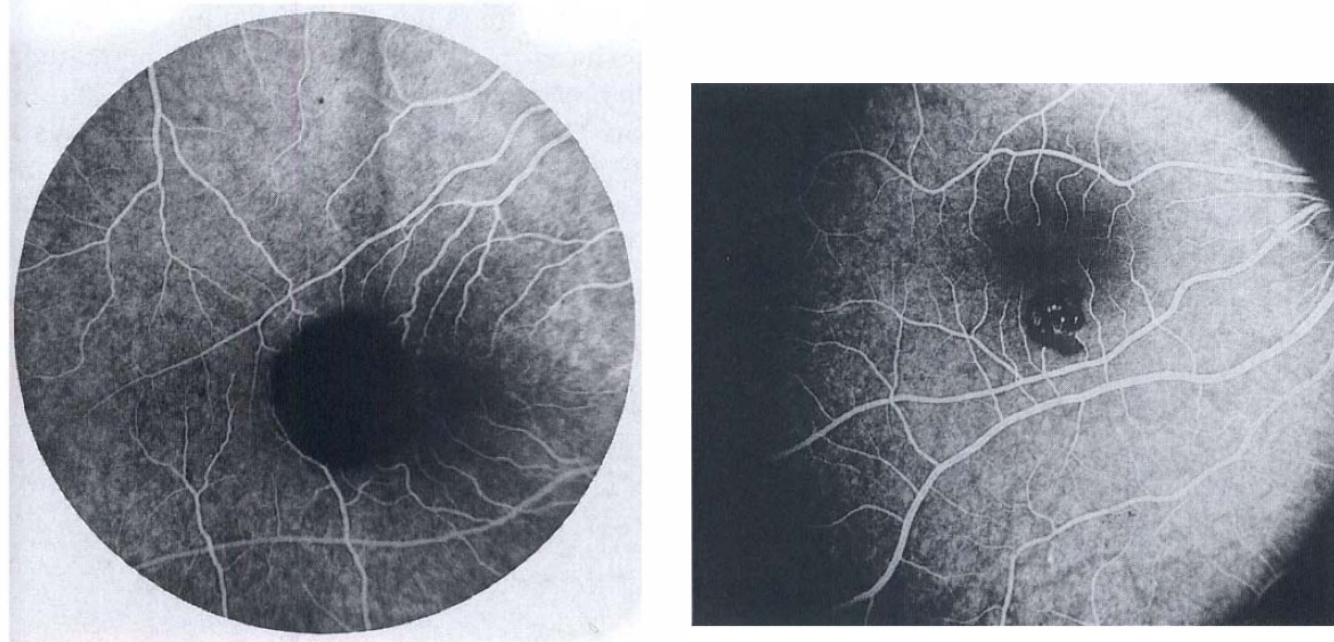

b

$\mathrm{d}$

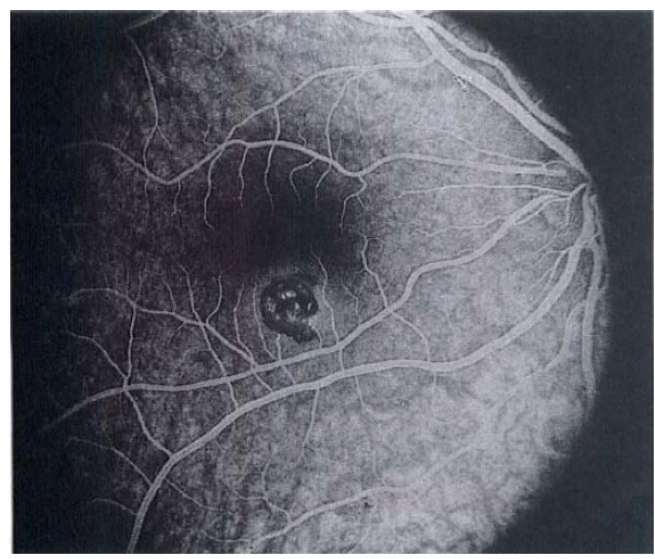

Fig. 2. Retinal pigment epithelial hamartoma. A, $B$, and C Case 3 Compare with Fig $1 B . C, D$, and E Case 7 Compare with Fig $1 C$. 
an admixture of glial, capillary, and pigment epithelial proliferation and hypertrophy. ${ }^{3,10,11}$ Cords of RPE cells are insinuated throughout the tumour and extend along the retinal blood vessels and nerve fibre layer. A fibrocellular glial membrane covers and is intimately connected to the irregular inner surface of the tumour.

B. Non-Papillary type. These tumours that may arise near or peripheral to the optic nerve head are often discovered in infants or children presenting with strabismus and severe monocular amblyopia. They are typically slightly elevated, pigmented, illdefined, variable sized lesions that are characterised by retinal thickening, increased number, dilation and tortuosity of the retinal vessels, an overlying epiretinal membrane, and underlying hyperpigmentation of the RPE (Fig. 5). 2,6,12,13 The margins of the pigmented portion of the tumour are feathery and blend imperceptibly into the surrounding normal orange coloured RPE. There is dragging of the neighbouring retina and retinal

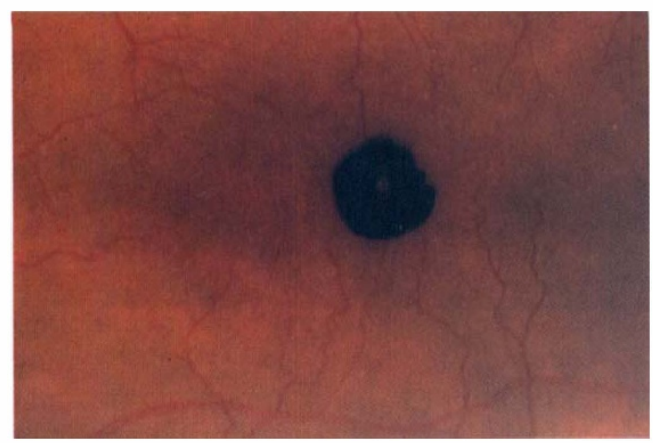

a

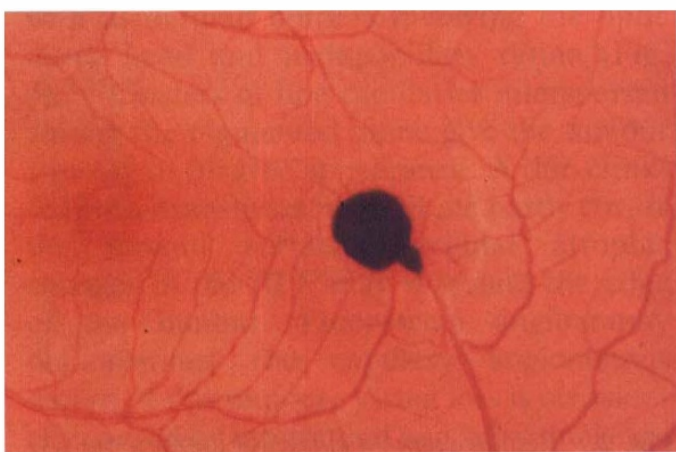

b

Fig. 3. Retinal pigment epithelial hamartoma. A. Case 10, B. Case 5, C. Case 9, D. Case 1. blood vessels toward the tumour. Unlike the papillary tumours, there is no extension of the RPE into the retinal portion of the tumour. Intraretinal and subretinal exudation are occasionally present. Angiography demonstrates the prominent retinal vascular changes and evidence of permeability alterations within the tumour. Histopathologically, the tumour consists of a fibrocellular membrane overlying dysplastic retina and hypertrophy of the RPE. There is no RPE extension into the dysplastic retina. ${ }^{14}$

\section{Melanotic Naevi of the Retinal Pigment Epithelium.}

A. Solitary Type-Congenital Hypertrophy of the Retinal Pigment Epithelium (CHRPE)

These are typically well demarcated, slightly elevated, dark grey or black, one to two disc diameters size, round or oval, placoid lesions with smooth or scalloped borders (Fig. 6). ${ }^{6,16,17}$ A non-pigmented halo

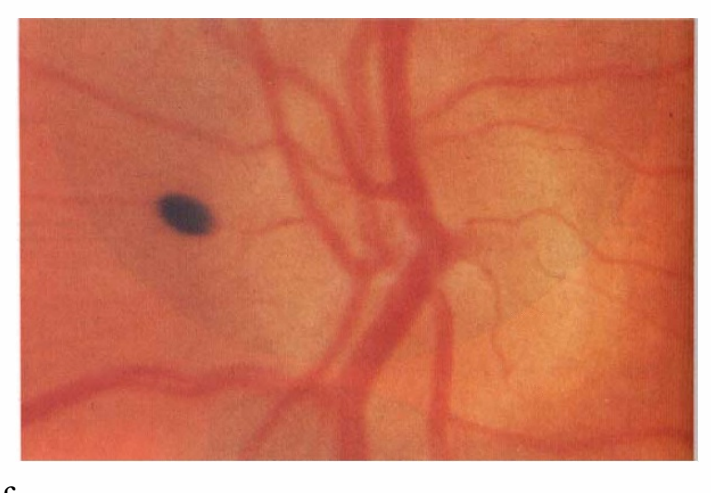

C

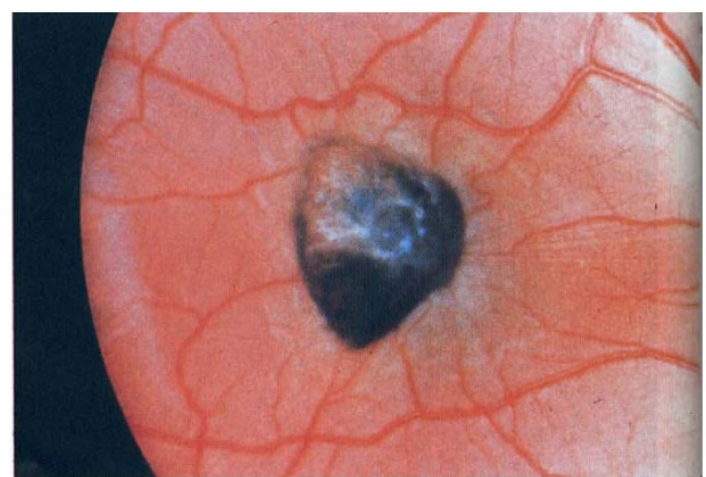

d 
may be present near their margin. Large lesions involving almost one-quarter of the fundus occasionally occur. A visual field defect corresponding with the lesion may be demonstrable, particularly. in older patients. ${ }^{17}$ Hypopigmented or non-pigmented lacunae are often present and may increase in size. Some lesions may be almost completely depigmented with only a thin rim of pigment at their margin. Concentric enlargement of the lesion occasionally occurs. ${ }^{18,19}$ Solitary lesions typically occur in one eye of otherwise normal patients, Multiple, widely separated, solitary, oval lesions with peculiar fishtail-shaped hypopigmented

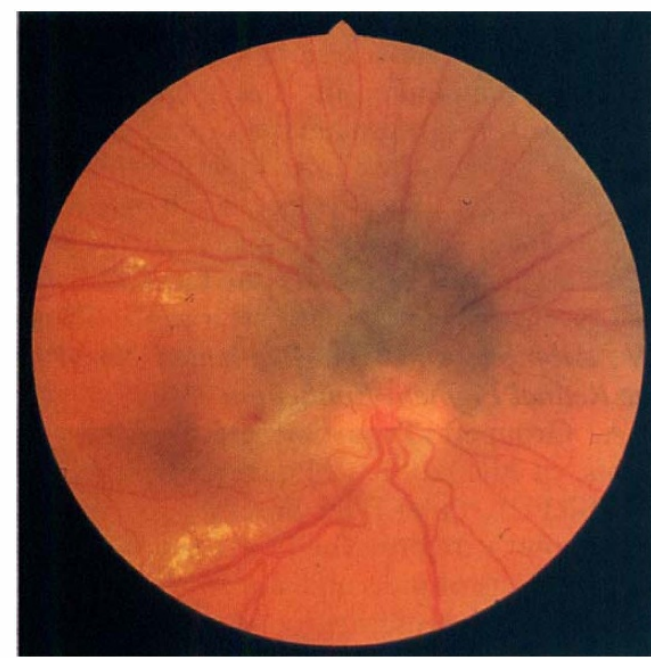

a

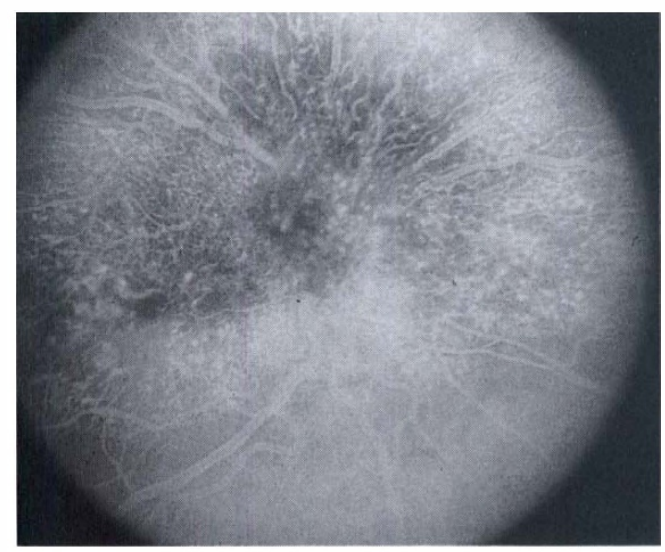

b

Fig. 4. $A$. and B. Combined retinal pigment epithelial and retinal hamartoma, papillary type. change at one or both ends of the lesion may occur in both eyes of multiple family members with Gardner syndrome, an autosomal dominant disorder characterised by multiple polyps of the intestinal tract, and other anomalies of bone and skin (Fig. 7). 20,21,22

Fluorescein angiography shows obstruction of the choroidal fluorescence corresponding with the pigmented portion of the tumour and hyperfluorescence in the areas of depigmentation, and occasionally may demonstrate alterations in the structure and permeability of the retinal vessels overlying these lesions. ${ }^{23}$

Histopathologically these lesions consist of a single layer of enlarged RPE cells filled with round macromelanin granules, thicken-
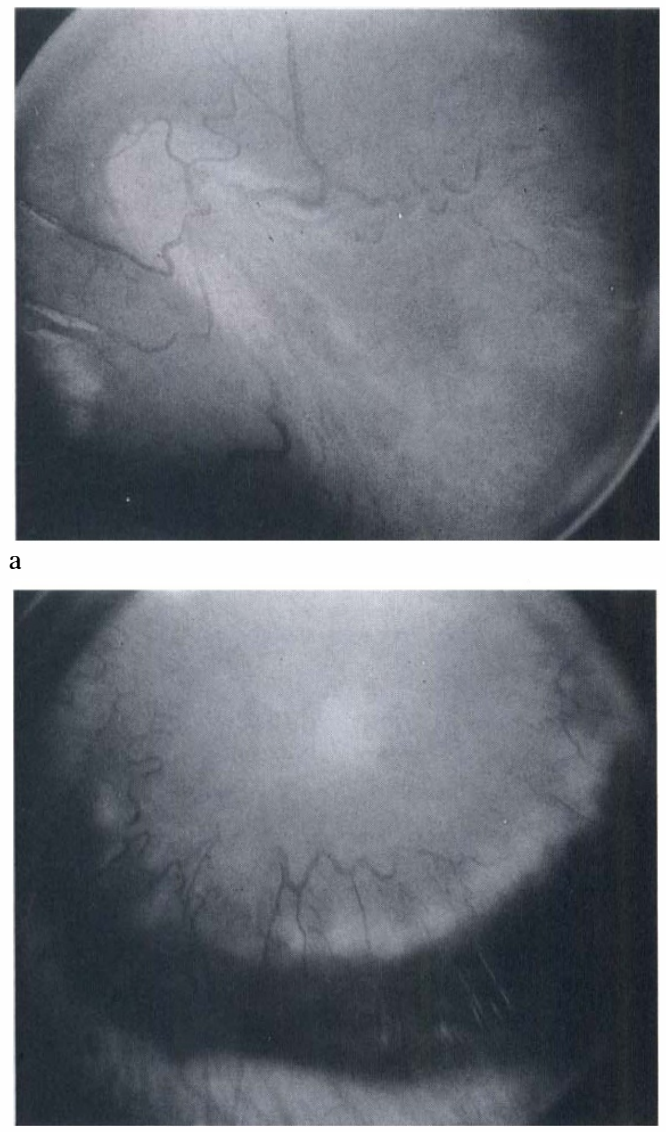

b

Fig. 5. Combined retinal pigment epithelial and retinal hamartoma, non-papillary type in a 30 month-old girl with mulitple cafe-au-lait spots. 


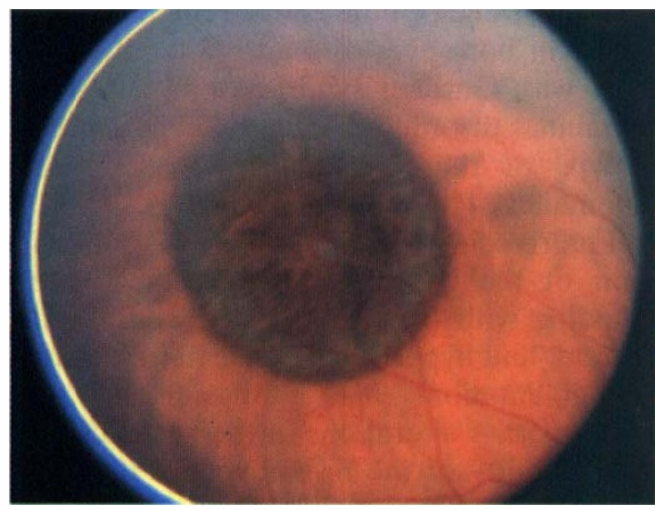

a

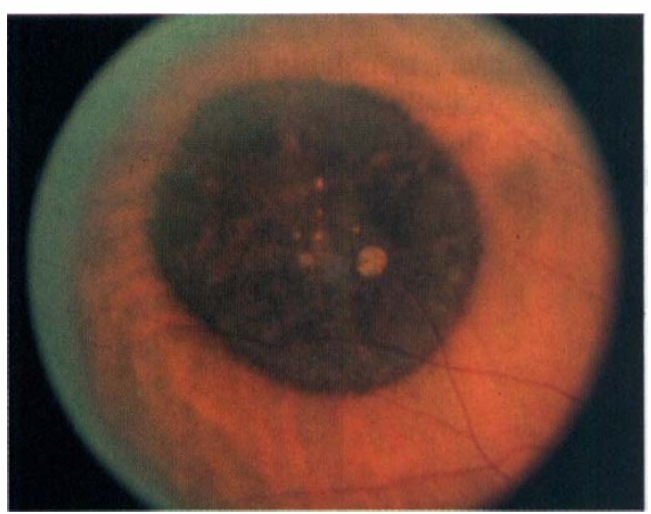

b

Fig. 6. A. and B. Congenital hypertrophy of the retinal pigment epithelium showing growth over a 3-year-period.

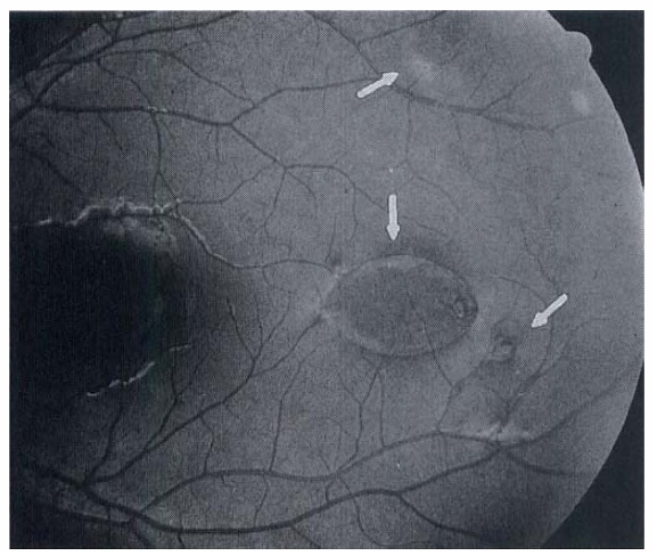

Fig. 7. Familial congenital hypertrophy of the retinal pigment epithelium. Note multiple lesions (arrows) in this 8-year-old boy. ing of the underling Bruch's membrane, and varying degrees of degeneration of the overlying outer retina. ${ }^{17,24}$ Proliferation and intraretinal migration of the RPE may occasionally occur. ${ }^{25}$ There is loss of the RPE in the fenestrated areas. ${ }^{17,24}$

B. Grouped Type-Congenital Grouped Pigmentation of the Retinal Pigment Epithelium, 'Bear Tracks.'

These are groups of small variable sized, sharply circumscribed, round, oval, or geographic, dark grey or black spots caused by hypertrophy of the RPE, often organised in a pattern simulating animal foot prints (Figs $8,9,10) .{ }^{26,27,28,29}$ They are often confined to one sector of the fundus with the smaller spots usually located at the apex toward the posterior pole. Most lesions vary from 0.1 to 0.5 disc-diameters in size. Gigantiform lesions several disc diameters or larger may occur (Fig. 8). They infrequently affect the macular area. They occasionally occur in association with other anomalies of eye and other organs, ${ }^{30,31,32}$ and may be familial. ${ }^{33}$

IV. Albinotic and Non-Pigmented Naevi of the Retinal Pigment Epithelium

A. Grouped Type-Congenital Albinotic Spots of the Retinal Pigment Epithelium (CASRPE), 'Polar Bear Tracks.'

Sharply circumscribed placoid, chalky white lesions of the same size, shape and distribution of congenital grouped pigmentation of the RPE rarely may occur in one or both eyes of typically asymptomatic, healthy children or adults (Figs 10,11,12,13). ${ }^{2}$

Biomicroscopically, they appear to lie at the level of the RPE. The lesions may be uniformly thick or may have a dimpled appearance because of greater concentration of the white pigment near their periphery. Choroidal vessels may be visible beneath some hypopigmented lesions. Some melanotic or partly melanotic spots may accompany the albinotic spots (Figs 11,12 and 15). In some patients virtually all of the RPE spots contain neither melanin or white pigment (Fig. 14). The natural course and histopathology of these lesions is unknown.

B. Solitary Type-Peripheral Retinal Albinotic Spots; Congenital Hypomelanotic Freckle. 
These are solitary, circumscribed, round, white lesions, one-fourth to one disc diameter in size, usually located in the midperiphery of the fundus at the level of the RPE (Fig. 16) ${ }^{6,34,35}$ Underlying choroidal vessels are usually visible. Although ophthalmoscopically they may be indistinguishable from the advanced atrophic form of CHRPE,

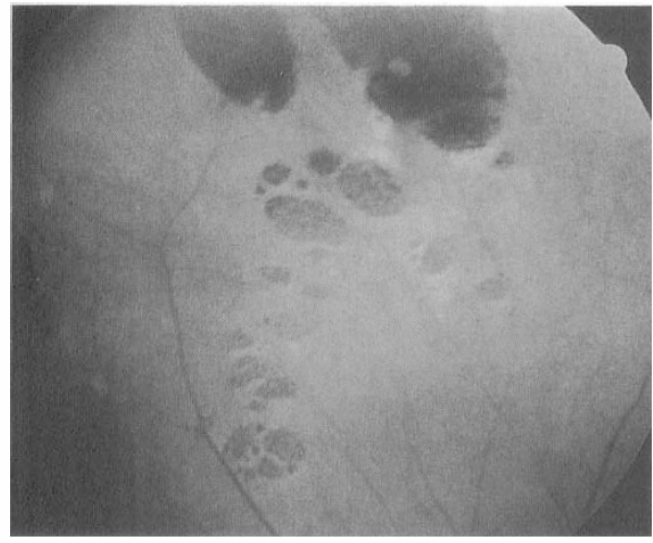

Fig. 8. Congenital grouped pigmentation of the retinal pigment epithelium with large lesion. histopathologically they differ from the latter lesions in that they consist of an intact nonpigmented RPE and normal overlying retina and underlying choroid.

\section{Observations}

I. Retinal Pigment Epithelial Hamartoma (RPEH)

Table 2 summarises the findings in ten patients ranging in age from 8 to 57 years. Most were asymptomatic and had normal or near normal acuity in the affected eye. The opposite eye was normal in all patients. Two were children with amblyopia and strabismus. Other patients, who were asymptomatic, had evidence of mild amblyopia. A solitary, circumscribed, nodular, jet-black intraretinal tumour was present in the macular region of nine patients and in the nasal juxtapapillary area in one patient (Figs $1,2,3)$. All but one tumour was one-half to one disc diameter in size. This latter lesion was the smallest and involved the inner half of the retina where it enveloped the overlying retinal vessels. All other lesions appeared to involve the full thickness of the retina and to

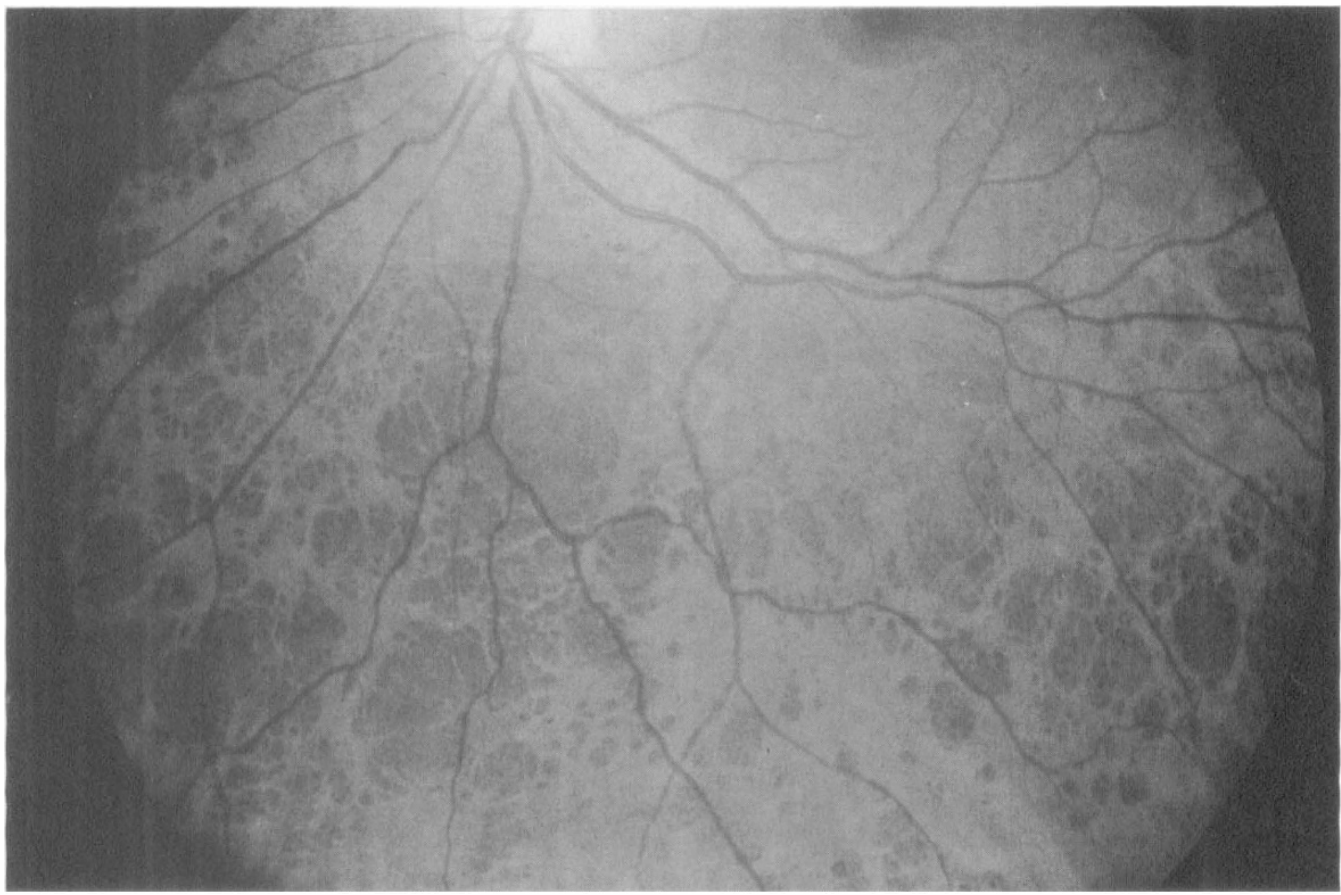

Fig. 9. Bilateral widespread congenital grouped pigmentation of the retinal pigment epithelium. 
Table II Ten patients with a retinal pigment epithelial hamartoma (congenital pigment epithelial adenoma; primary pigment epithelial hyperplasia)

\begin{tabular}{|c|c|c|c|c|c|c|c|}
\hline $\begin{array}{l}\text { Case } \\
\text { No. }\end{array}$ & $\begin{array}{c}\text { Age-Sex } \\
\text { (years) }\end{array}$ & $\begin{array}{l}\text { Signs and } \\
\text { Symptoms }\end{array}$ & $\begin{array}{c}\text { Eye } \\
\text { Affected }\end{array}$ & $\begin{array}{l}\text { Visual } \\
\text { Acuity }\end{array}$ & Location & $\begin{array}{l}\text { Associated } \\
\text { Findings }\end{array}$ & $\begin{array}{c}\text { Duration } \\
\text { Follow-up } \\
\text { (years) }\end{array}$ \\
\hline 1. & $8 \mathrm{~F}$ & esotropia & OD & $20 / 400$ & $\begin{array}{l}\text { central } \\
\text { macula }\end{array}$ & none & 0 \\
\hline 2. & $11 \mathrm{~F}$ & $\begin{array}{l}\text { esotropia } \\
\text { amblyopia }\end{array}$ & OD & $20 / 50$ & $\begin{array}{l}\text { paracentral } \\
\text { macula }\end{array}$ & none & 5 \\
\hline 3. & $12 \mathrm{~F}$ & asymptomatic & OD & $20 / 25$ & $\begin{array}{l}\text { paracentral } \\
\text { macula }\end{array}$ & $\begin{array}{c}\text { anomaly } \\
\text { nerve head }\end{array}$ & 13.5 \\
\hline 4. & $14 \mathrm{~F}$ & asymptomatic & OD & $20 / 15$ & $\begin{array}{l}\text { paracentral } \\
\text { macula }\end{array}$ & none & 0 \\
\hline 5. & $17 \mathrm{~F}$ & asymptomatic & OS & $20 / 25$ & $\begin{array}{l}\text { paracentral } \\
\text { macula }\end{array}$ & none & 0 \\
\hline 6. & $16 \mathrm{M}$ & asymptomatic & OS & $20 / 25$ & $\begin{array}{l}\text { paracentral } \\
\text { macula }\end{array}$ & none & .3 \\
\hline 7. & $22 \mathrm{~F}$ & asymptomatic & OD & $20 / 20$ & $\begin{array}{l}\text { paracentral } \\
\text { macula }\end{array}$ & none & 1 \\
\hline 8. & $30 \mathrm{~F}$ & asymptomatic & OS & $20 / 15$ & $\begin{array}{l}\text { paracentral } \\
\text { macula }\end{array}$ & none & 0 \\
\hline 9. & $38 \mathrm{~F}$ & amblyopia & OD & $20 / 30$ & $\begin{array}{l}\text { nasal juxta- } \\
\text { papillary area }\end{array}$ & none & 7 \\
\hline 10. & $57 \mathrm{M}$ & $\begin{array}{l}\text { blurred } \\
\text { vision }\end{array}$ & OS & $20 / 25$ & $\begin{array}{l}\text { paracentral } \\
\text { macula }\end{array}$ & none & 3.5 \\
\hline
\end{tabular}
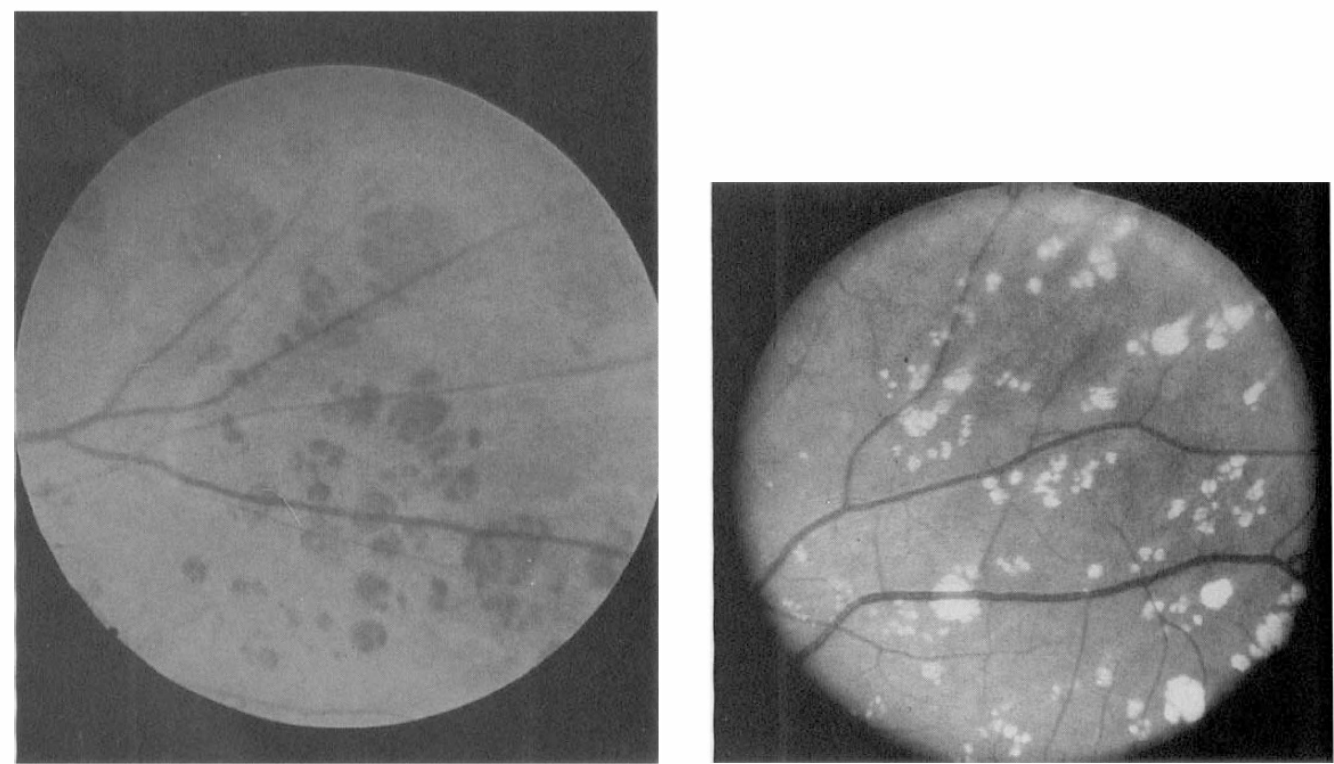

Fig. 10. A. Congenital grouped pigmentation of the retinal pigment epithelium. B. Congenital grouped albinotic spots of the retinal pigment epithelium (Case 14). 
extend through the internal limiting membrane in an umbrella-shaped fashion onto the inner retinal surface. This latter portion of the tumour usually had a brownish-black colour. Several tumours had a few isolated flecks of black pigment on the retinal surface adjacent to the tumour. There was no abnormality in the RPE and choroid around the base of the lesions. No exudation or haemorrhage was present. Only one of the tumours involved the centre of the macula (Fig. 3). It was the only one associated with a thin over- lying semitranslucent membrane. Fluorescein angiography was done in six eyes and in all showed obstruction of the normal retinal and choroidal fluorescence in the area of the tumour. In one case, there was evidence of small incompetent blood vessels near the tumour surface (Figs 1c and 2, Case 7), and three others showed evidence of late staining indicating variable permeability alterations within the depth of the tumour. Five tumours observed for one to fifteen years have shown no change.

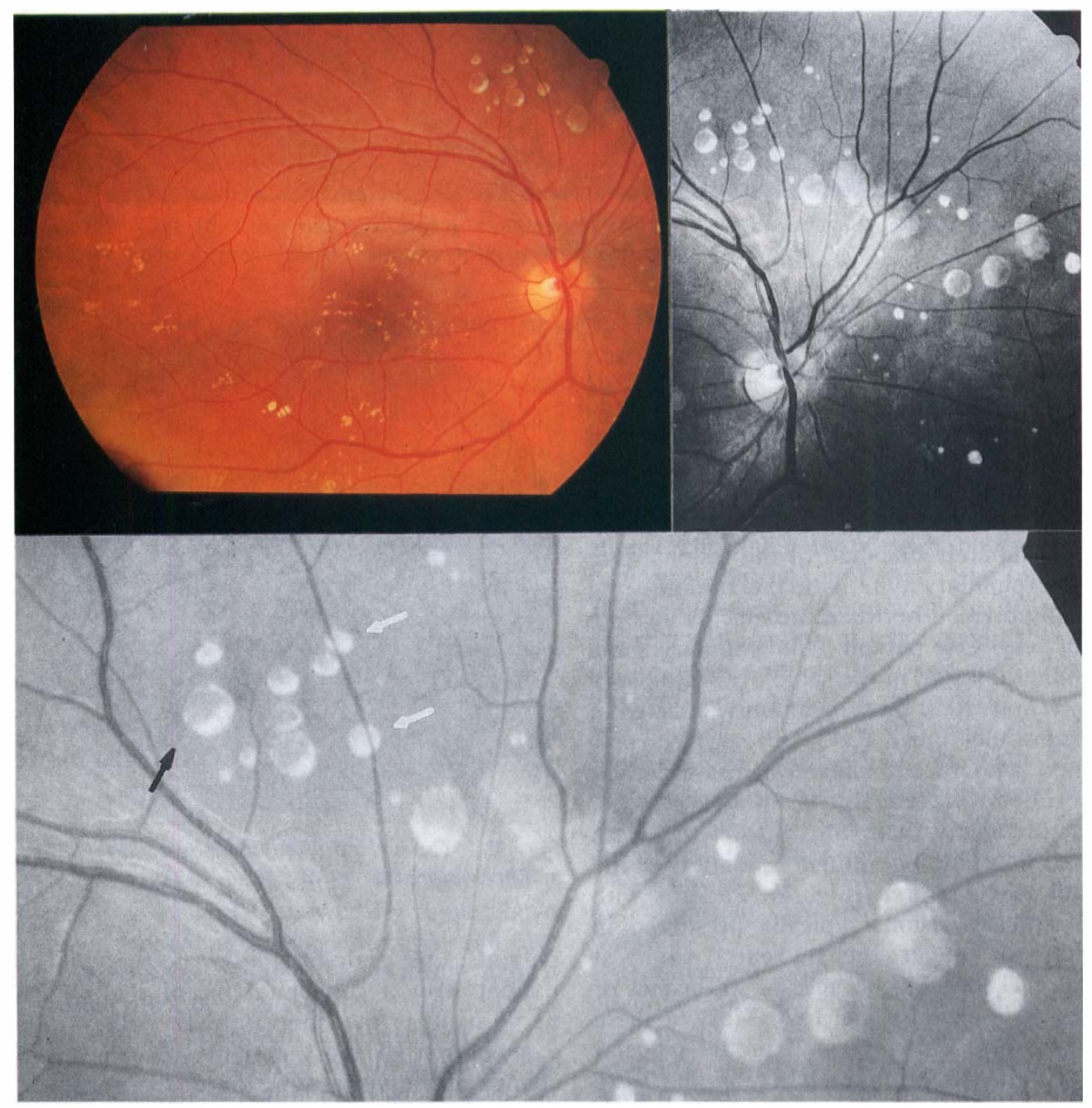

Eig. 11. Congenital grouped albinotic spots of the retinal pigment epithelium. Case 11, right eye. Lower photographs magnified. Note incomplete white pigmentation of some lesions (black arrows) and focal narrowing of retinal vessels (white arrows). 


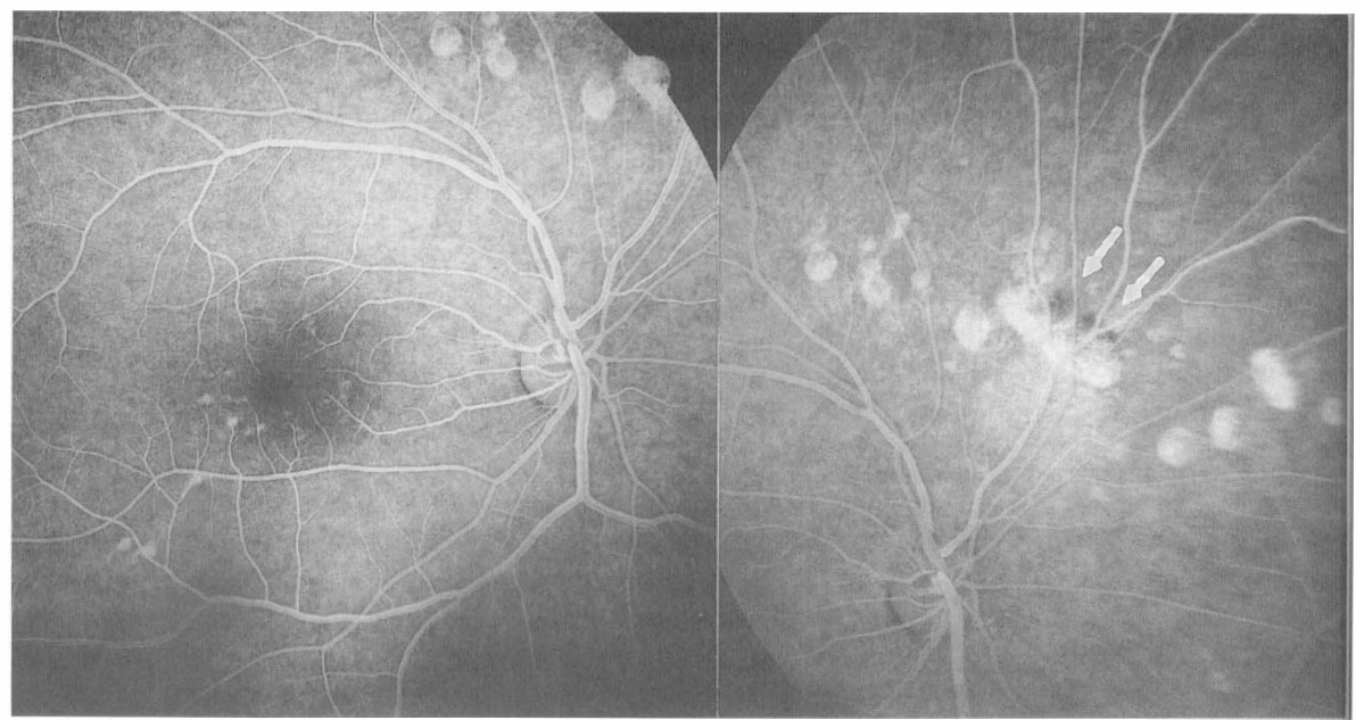

Fig. 12. Angiogram Case 11, right eye. Note evidence of partial hyperpigmentation of some of the lesions (arrow).

\section{Combined Retinal Pigment Epithelial and} Retinal Hamartoma (CRPE-RH)

In 1984, Dr Karen Senikowich and I reviewed the findings in 35 patients followed one to nineteen years with these lesions at the Bascom Palmer Eye Institute. The race distribution involved 34 whites, and one Oriental. There was no sex predilection. Approximately one-half of the lesions were of the papillary type with the others being equally divided between the macula and the periphery. One patient had a papillary and a peripheral lesion in the same eye. The papillary lesions were most commonly detected in young adults (mean age of 19 years) who presented with recent unilateral loss of vision associated with retinal stria. In several cases, loss of acuity was also associated with intraretinal and subretinal exudation in the papillomacular area (Fig. 4). Patients with nonpapillary lesions typically presented in childhood (mean age 8 years, youngest patient 11 months) because of strabismus or recently detected visual loss. Most of these lesions were either located in the macular area or in the peripheral fundus and were associated with ectopia of the macula that was dragged toward the tumour. Eight lesions were discovered in asymptomatic

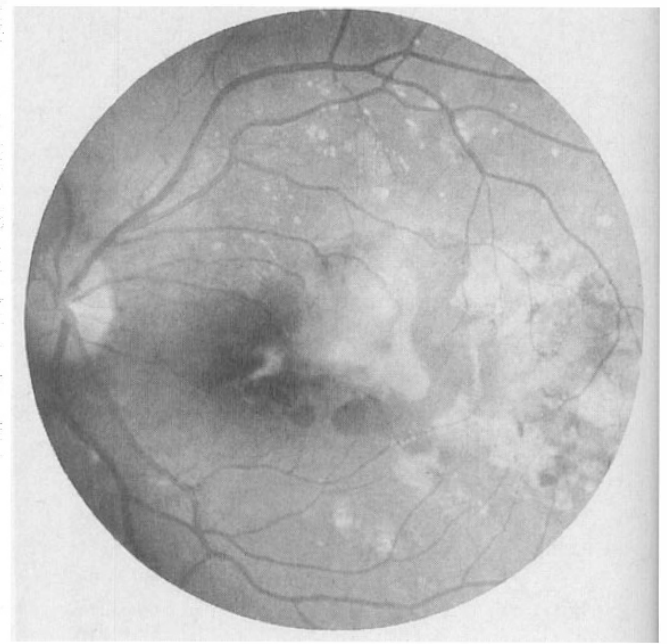

Fig. 13. Case 12. Subretinal neovascularisation and haemmorhage.

patients. One peripheral lesion occurred in a patient with a congenital pit of the optic nerve head in the opposite eye. Follow-up examination in most patients revealed no change in the visual function or the appearance of the lesion. Four eyes that initially had visual acuity of $20 / 60$ or better declined to levels of $20 / 100$ or worse because of further 


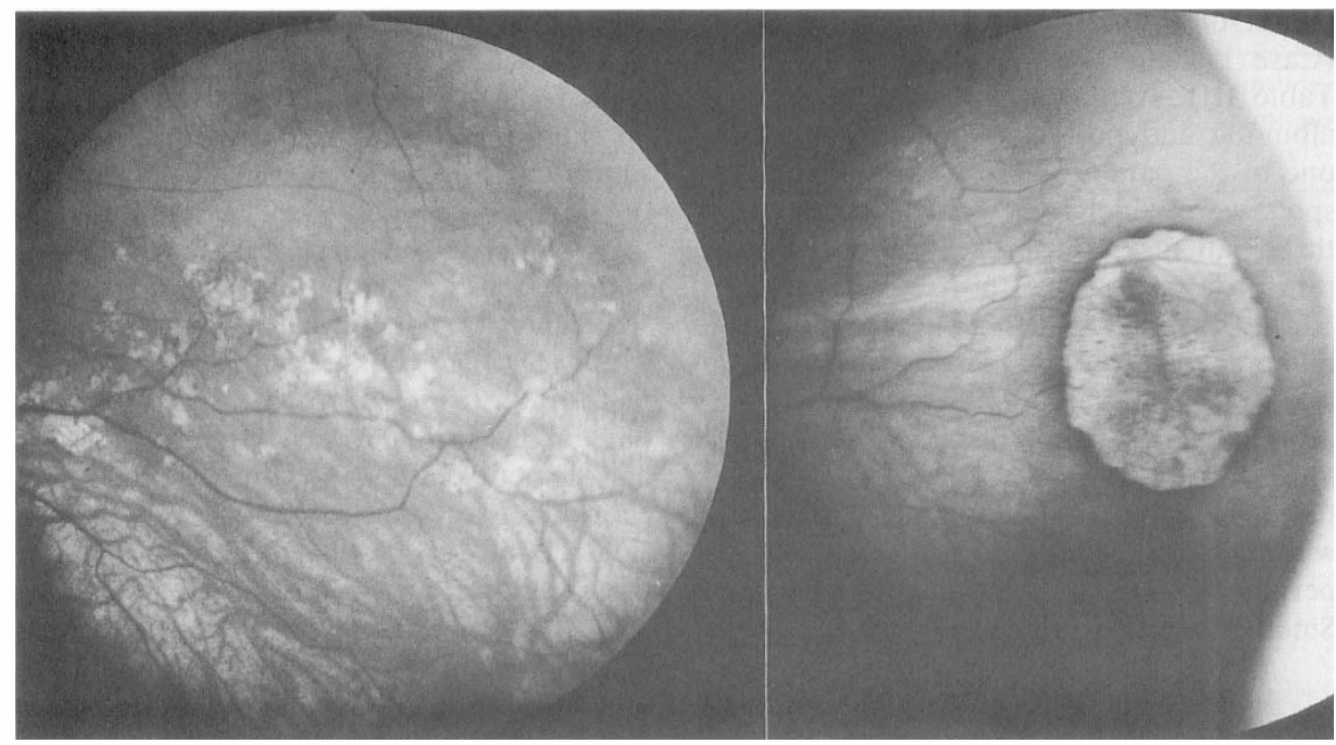

Fig. 14. Case 16. Congenital grouped non-pigmented retinal pigment epithelial spots (left) and solitary partly pigmented congenital hypertrophy of the retinal pigment epithelium (right).

contraction of the epitumoral membrane. One patient developed haemorrhagic retinal detachment, neovascular glaucoma, and had enucleation of a blind painful eye (Fig 5). Forty percent of the eyes retained vision of $20 / 40$ or better. The medical and family history of most patients was negative. Two patients had had excision of localised facial haemangiomas. Two children had multiple cafe-au-lait spots, one boy had x-linked juvenile retinoschisis. Since that review, I have seen fundus photographs courtesy of Dr Lanning Kline and Dr Millicent L Palmer of two children with von Recklinghausen's disease and bilateral combined hamartomas involving the macular areas.

\section{Melanotic Naevi of the RPE}

(A.) Solitary type (CHRPE). None of these lesions in patients followed by myself have shown any enlargement. I was able to locate in the Bascom Palmer Eye Institute photographic files only one patient whose lesions has shown concentric enlargement which occurred over a period of three years (Fig. 6 ). It showed in addition an increase in the area of fenestrated atrophy. I have seen multiple widely scattered, oval, solitary lesions, typical of those seen in Gardner syndrome, in three members of one family, including a thirty year mother, her eight-year-old son, and her ten-year-old daughter. ${ }^{2}$ A medical evaluation failed to show evidence of intestinal polyposis or other stigmata of the disease.

(B.) Grouped type (CHRPE). Only nine cases of 'bear tracks' are included among the almost 100,000 patients with photographic records at the Bascom Palmer Eye Institute. They ranged in age from 11 to 59 years. There was no apparent relationship between the uniformity and density of pigmentation of the spots and the age of the patient. All but one patient had lesions involving only one eye (Fig. 9). Three had unusually large lesions (Fig. 8). One patient with normal visual function had lesions widely scattered throughout the fundi of both eyes (Fig. 9).

\section{Albinotic and Non-Pigmented RPE} Naevi.

(A.) Grouped type (CASPRE). Grouped albinotic spots were seen in four patients at the Bascom Palmer Eye Institute and in photographs of one patient courtesy of Dr Alvaro Rodriguez (Fig. 10B, Case 14, Table III). Grouped non-pigmented spots were observed in the photographic records of three patients provided courtesy of Dr Lee 
Anderson (Case 16), Dr Lawrence Yannuzzi (Case 17), and Dr Richard Fish (Case 18, Table III). At the time of discovery of the albinotic and non-pigmented spots, all but one of the patients were asymptomatic. The spots were widely scattered in both eyes in three patients and were centred in one quadrant or less in six eyes in five patients (Figs. $10,11,12,13,14$ and 15). Three patients with bilateral involvement showed evidence of black, as well as albinotic spots. In two, only a few black or partly black spots were present. In one 64-year-old patient (Case 15), there was widespread admixture of black and white spots scattered for $360^{\circ}$ in the peripheral fundus of both eyes (Fig. 15). Small albinotic spots were present in the

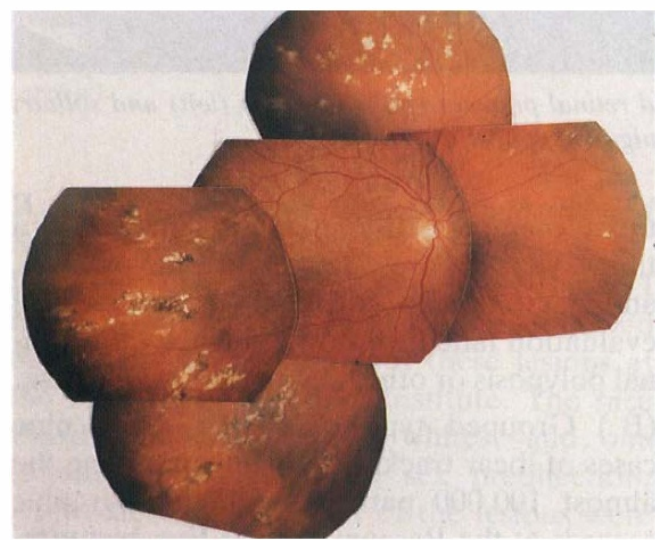

Fig. 15. Case 15. Congenital grouped melanotic and albinotic spots of the retinal pigment epithelium.

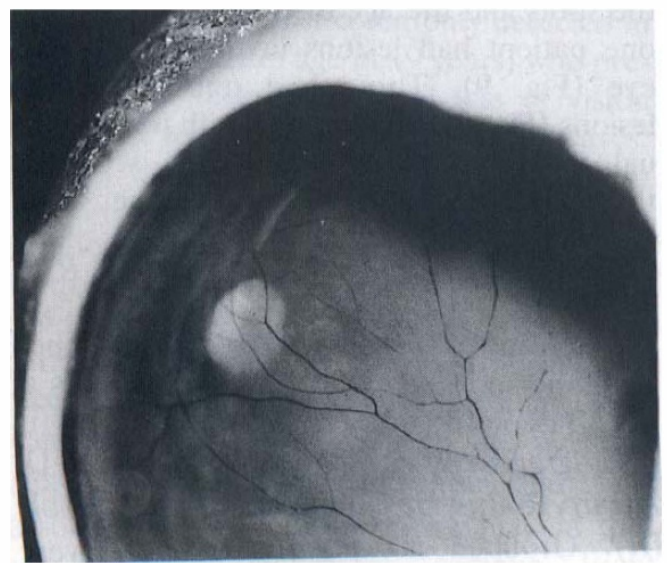

Fig. 16. Solitary congenital non-pigmented retinal pigment epithelial naevus. macular region of five eyes that contained many groups of larger spots peripherally (Figs 11, 12). Most of the spots appeared to be slightly elevated, chalky white, placoid, subretinal lesions. There was focal narrowing of the major retinal vessels as they coursed over some of the larger lesions (Fig. 11). Some lesions appeared to be slightly de-pressed centrally where the lesions were less white (Fig. 11). Other lesions showed complete absence of either the stark white colour, or the normal orange colour of the retinal pigment epithelium, and the underlying choroidal structures were exposed to view (Figs 11 and 14). Virtually all of the lesions in three children and young adults (Cases 16, $17,18)$ appeared to be free of either melanin or white pigment (Fig. 14). One patient had in addition a solitary partly depigmented CHRPE lesion (Fig. 14).

Fluorescein angiography showed varying degrees of early hyperfluorescence corresponding with most of the albinotic lesions and no evidence of late staining (Fig. 12). More densely white lesions showed less transmission of choroidal fluorescence.

In two patients, electroretinographic, electro-oculographic, and dark adaptometric findings were normal.

The spots in one 64-year-old patient (Case 15) were initially detected at age 9 years. Unfortunately no photographs were available prior to his presentation in Miami complaining of mild visual loss. His visual acuity was $20 / 25$ OU. In addition to mild cataracts, he had innumerable peripheral albinotic and black spots (Fig. 15), as well as large irregular areas of mild depigmentation of the pigment epithelium in the macular regions. $\mathrm{He}$ refused electrophysiologic studies.

An 11-year-old girl (Case 12) with bilateral widespread spots returned at age 14 years because of severe visual loss caused by subretinal neovascularisation in the left eye (Fig. 13).

(B.) Focal Type (CASRPE). While doing gross examination of a fresh autopsy eye of an adult patient, I noted an oval white subretinal lesion in the peripheral fundus (Fig. 16). I was surprised to find on histopathologic examination that the lesion was 
Table III Eight patients with grouped albinotic naevi of the retinal pigment epithelium

\begin{tabular}{|c|c|c|c|c|c|c|c|c|}
\hline \multirow{2}{*}{$\begin{array}{l}\text { Case } \\
\text { NO. }\end{array}$} & \multirow{2}{*}{$\begin{array}{l}\text { Age/Sex } \\
\text { (years) }\end{array}$} & \multirow{2}{*}{$\begin{array}{l}\text { Signs and } \\
\text { Symptoms }\end{array}$} & \multirow{2}{*}{$\begin{array}{c}\text { Eye } \\
\text { Affected }\end{array}$} & \multicolumn{2}{|c|}{$\begin{array}{l}\text { Visual } \\
\text { Acuity }\end{array}$} & \multirow{2}{*}{$\begin{array}{c}E R G \& E O G \\
\text { Dark } \\
\text { Adaptation }\end{array}$} & \multirow{2}{*}{$\begin{array}{l}\text { Associated } \\
\text { Findings }\end{array}$} & \multirow{2}{*}{$\begin{array}{l}\text { Duration } \\
\text { Follow-up } \\
\text { (years) }\end{array}$} \\
\hline & & & & $O D$ & $O D$ & & & \\
\hline 11. & $15 \mathrm{~F}$ & asymptomatic & OU & $20 / 20$ & $20 / 20$ & normal & none & 1 \\
\hline 12. & $11 \mathrm{~F}$ & asymptomatic & OU & $20 / 20$ & $20 / 20$ & normal & $\begin{array}{l}\text { age } 14 \\
\text { developed sub- } \\
\text { retinal new } \\
\text { vessels OS, } \\
\text { VA 9/200 }\end{array}$ & 6 \\
\hline 13. & $22 \mathrm{M}$ & asymptomatic & OD & $20 / 20$ & $20 / 20$ & not done & none & 0 \\
\hline 14. & $40 \mathrm{~F}$ & asymptomatic & OS & $20 / 20$ & $20 / 20$ & not done & none & 0 \\
\hline 15. & $64 \mathrm{M}^{*}$ & mild blurring & OU & $20 / 25$ & $20 / 25$ & not done & $\begin{array}{l}\text { mild cataracts } \\
\text { mild pigment } \\
\text { atrophy macula } \\
\text { OU }\end{array}$ & 55 \\
\hline 16. & $17 \mathrm{M}$ & asymptomatic & OU & $20 / 15$ & $20 / 15$ & not done & $\begin{array}{l}\text { solitary CHRPE } \\
\text { OS }\end{array}$ & 0 \\
\hline 17. & $16 \mathrm{~F}$ & asthenopia & OS & $20 / 20$ & $20 / 20$ & not done & none & 0 \\
\hline 18. & $8 \mathrm{M}$ & asymptomatic & OD & $20 / 25$ & $20 / 25$ & none & none & 3 \\
\hline
\end{tabular}

*age 9 years, was asymptomatic when retinal spots were first detected.

characterised by the presence of a focal area of intact but nonpigmented RPE lying between normal choroid and retina. Unaware that the gross and histopathologic findings in two identical lesions in a 59-year-old and 64year-old adult had been described as 'peripheral albinotic spots, ${ }^{34}$ I labelled the lesion 'congenital amelanotic freckle of the RPE.' 2,6 There was no evidence of abnormal material stored in the affectd RPE in any of these three lesions. Clinically they appear as focal sharply circumscribed nonpigmented or hypopigmented spots by virtue of the absence of the orange coloured melanin in the RPE and the high visibility of the white sclera through the thin peripheral choroid. Large choroidal blood vessels are visible within the lesions. I have seen many such lesions but have been uncertain whether they represented completely depigmented CHRPE or CASPRE lesions. I have not recognised a solitary opaquely white CASPRE lesion which obstructed all details of the underlying choroid.

\section{Discussion}

The RPE normally grows at a slow rate, yet when challenged, is one of the most reactive of human tissues. These reactions include hyperplasia, hypertrophy, migration, metaplasia, and atrophy. All are found in the cytologic makeup of the developmental lesions of the RPE. It is because of the potential for a variety of postnatal injuries to incite reactive RPE changes, which on occasion may simulate a developmental lesion, that the diagnosis of the latter, either clinically or histopathologically is always one of presumption. This is not unique in regard to the RPE. Similar difficulties are encountered in the case of retinal astrocytic and capillary angiomatous hamartomas. The chance of misdiagnosis is lessened if the lesion: (1) is discovered in childhood, (2) is typical, (3) is unassociated with evidence of other postnatal disease in the eye, (4) is associated with evidence of other congenital ocular or systemic defects, (5) shows no growth.

Since none of the ten intraretinal lesions diagnosed clinically in this study as RPEH have been examined histopathologically, their morphology, as well as pathogenesis are still subject to verification. Five of the tumours occurred in patients 16 years or younger. Two had amblyopia and one had a congenital deformity of the optic nerve head in the affected eye. Four patients with extrafoveal lesions had mild loss of vision in 
the affected eye. I could find no previous report of similar lesions. None of the affected eyes had evidence of changes in the surrounding RPE and choroid or other evidence of acquired disease. None of the five lesions followed for one to fifteen years has changed. Could the melanocytes within these ocular intraretinal and preretinal tumours be of uveal rather than pigment epithelial origin? Although uveal melanocytomas may have the same features in regard to their colour and extension into the anterior surface of the optic nerve head and juxtapapillary retina, they have not been observed to extend into the full thickness of the retina away from the optic nerve head. Should such extension occur, biomicroscopic evidence of the tumour within the choroid around its base would be expected. If RPEH were a reactive postnatally acquired lesion then we should expect to see its gross morphology duplicated by the many diseases that cause reactive changes in the pigment epithelium. Reactive migration of RPE into the retina occurs under many circumstances associated with loss of the outer retinal receptors, e.g., retinitis pigmentosa, traumatic chorioretinopathy and chronic secondary retinal detachment associated with choroidal tumours, and age-related macular degeneration. Rarely, however, does it produce a tumefaction of hyperplastic pigment epithelium and when it does, evidence of the underlying disease is present adjacent to the lesions. ${ }^{36}$ Figure 14 depicts the only example of a pseudoadenomatous proliferation of RPE simulating RPEH that I have seen. (courtesy of Dr Helmut Buettner). It occurred after photocoagulation of a subretinal neovascular membrane in a patient with the presumed ocular histoplasmosis syndrome.

Several eyes containing black adenomas of the RPE mistaken for uveal melanocytomas and melanomas have been studied histopathologically. ${ }^{37,38,39,40,41}$ These lesions were larger than the RPEH lesions in this report, and they were primarily subretinal rather than intraretinal tumours. Although there was a presumption of their recent growth, documentation was usually absent. The histopathologic criteria for distinguishing neoplastic from reactive RPE tumours are not completely reliable, ${ }^{41}$ and there are no reliable histopathologic criteria to distinguish an acquired from a congenital adenoma of the RPE. Therefore, some of the lesions reported as adenomas may have been of developmental origin.

Cardell and Starbuck ${ }^{3}$ were the first to suggest the hamartomatous nature of a juxtapapillary tumour that was subsequently included in a broader spectrum of tumours termed, 'combined retinal pigment epithelial and retinal hamartomas. ${ }^{5,6}$ Recent reports have presented further evidence of the hamartomatous nature of these lesions. ${ }^{8,9,12,13,14,42,43,44}$

Laqua and Wessing ${ }^{14}$ objected to use of 'hamartoma' to describe these often slightly elevated lesions. Some, however, may have a more nodular configuration. ${ }^{6,44}$ Associated congenital anomalies and disorders have included optic disc colobomata, pits, and drusen; sex-linked juvenile retinoschisis, incontinentia pigmenti, and multiple cafe au lait spots. ${ }^{2,6,8}$ In addition to the four children with evidence of neurofibromatosis mentioned previously, a patient described as having cafe au lait spots of the fundus in association with neurofibromatosis had a CRPERH in the macula and a large solitary CHRPE in the same eye. ${ }^{45}$

When the pigmented component is minimal, the papillary CRPE-RH may be difficult to distinguish from a juxtapapillary capillary angioma (von Hippel's tumour). Capillary angiomas often do not have an epitumoural membrane, a cardinal feature of CRPE-RH. Capillary angiomas appear to have a greater growth potential than CRPERH. Although both are developmental capillary angiomatous lesions, there are no reports of a patient with CRPE-RH and other evidence of von Hippel-Lindau disease. A lightly pigmented CRPE-RH may also be simulated by an acquired focal contraction of an epiretinal membrane in response to a variety of retinal vascular inflammatory or other disorders. ${ }^{46}$

Retinal distortion caused by contraction of the vitreoretinal interface portion of CRPE$\mathrm{RH}$ is the primary cause of visual loss. The glial membrane on the tumour surface is intricately woven with the other components 
of the tumour and attempts at surgical removal are likely to be unsuccessful. ${ }^{47}$

Hypertrophy of the RPE may be a reactive response to a variety of stimuli. ${ }^{35}$ There is increasing evidence, however, that most solitary, as well as the grouped CHRPE lesions are of developmental origin, e.g., their association with neurofibromatosis, ${ }^{45}$ Gardner syndrome, ${ }^{20,21,22}$ autosomal dominant hyperreflexia and microcephaly, ${ }^{48}$ dyschondroplasia, ${ }^{30}$ cerebromacular degeneration, ${ }^{31}$ and macula coloboma. ${ }^{32}$

The occasional concentric enlargement of these lesions in adults does not necessarily exclude the possibility of their developmental origin. ${ }^{18,19}$ Hyperplastic, migratory, as well as atrophic reactive changes have been described histopathologically with these lesions in adults. ${ }^{17,24,35}$ These are probably acquired reactive changes and are analogous to similar reactive RPE changes, drusen formation, and choroidal neovascularisation that occurs overlying choroidal naevi. Choroidal neovascularisation has not yet been reported in CHRPE, but probably does rarely occur. None of these reactive changes nor the progressive atrophic changes in the overlying retina which occur in solitary CHRPE have been demonstrated either histopathologically or clinically in grouped CHRPE lesions. ${ }^{29}$ Using again the analogy to choroidal naevi, reactive changes are more likely to occur in the vicinity of larger developmental lesions, that perhaps interfere to a greater degree with the nutrition of neighbouring tissue.

Since only $2 \%$ or less of patients with solitary CHRPE have bilateral involvement, ${ }^{16,21}$ patients with multiple lesions should be investigated for evidence of Gardner syndrome. Although investigations of the family with multiple lesions observed in Miami failed to reveal evidence of the syndrome, they may develop systemic manifestations in the future. The average age of detection of intestinal polyposis is 30 years. $^{21}$

Until histopathologic information becomes available, we can only speculate as to the nature and pathogenesis of the albinotic spots in grouped CASRPE. The biomicroscopic and flourescein angiographic findings locate the lesion at the level of the RPE.
Their similar location, size, shape, and distribution to that of grouped CHRPE or bear tracks, suggest that they are anatomically and pathogenetically related. This is reinforced by their frequent coexistence in the same eye. Their apparent slight elevation and their chalky white colour that obscures underlying choroidal details, suggest that they may consist of hypertrophied RPE cells which are packed with white pigment, perhaps an abnormal form of melanin or one of its precursors, rather than macromelanin granules in the case of its pigmented counterpart. The wide variation in the amount of the white material in these lesions appears greater than that seen in grouped CHRPE. In spite of the apparent thickness and dense whiteness of many of the lesions, most of them transmit some of the background choroidal fluorescence angiographically. Whether the amount of white pigment changes with time is unknown. The fact that in three young patients all of the spots appeared to be free of both melanin and white pigment suggests that their state of nonpigmentation may have been present at birth. The focal narrowing of both retinal arteries and veins as they cross some large white spots suggests that these spots may affect in some way the diffusion of nutrients or metabolites.

Since choroidal neovascularisation is uncommon in children, it is probable that this complication occurred at the site of one of the albinotic lesions being followed in the 14 year-old girl with CASRPE.

The pattern of spots and the fluorescein angiographic changes in CASRPE appears similar to that reported by Kandori in patients with non-familial stationary night blindness, usually manifest only by mild changes in dark adaptation thresholds. ${ }^{49,50,51}$ Unlike CASRPE, the flecks were described as "dirty yellow" rather than white, and the disc-macular areas were not affected. All eight patients with grouped albinotic and non-pigmented RPE naevi included in this report denied nyctalopia and two had normal dark-adaptation studies.

It is tempting to suggest that there is a similar histopathogical relationship between the solitary and grouped form of CASRPE as there is in both forms of CHRPE. The 
limited clinical and histopathological information available concerning solitary albinotic spots suggests that in adults, most are focal areas of translucent non-pigmented RPE cells through which the choroidal vessels and white sclera are readily viewed.6,34 Of interest is the observation by Dr Richard Green of the same histopathologic findings in a 12-year-old girl with a peripheral albinotic spot (personal communication). The absence of any pigment in the RPE suggests that these solitary lesions may contain neither melanin nor white pigment from birth. Unlike solitary fenestrated CHRPE lesions in which the RPE and outer retinal elements are atrophic or missing in the areas of depigmentation, the retina, choroid, and non-pigmented RPE in solitary CASRPE are intact. It is unknown whether or not they may have at one time contained white pigment that gradually disappeared. If so, we can expect in the future to identify solitary white lesions with the same biomicroscopic features as the grouped white spots, probably in a child or young adult. There may be some difficulty in differentiating one of these opaque white lesions from a non-pigmented choroidal naevus.

The absence of histopathological evidence of abnormality of either the retina or choroid over these lesions suggests that visual field examination should be helpful in distinguishing them from the atrophic stage of CHRPE that biomicroscopically appears identical.

Any proposed classification of focal developmental anomalies of the RPE will have to be modified as more is learned concerning these disorders. In keeping with accepted nomenclature for developmental placoid lesions of the uveal tract, and as a means of simplification, use of the term 'naevus' for all of these placoid lesions of the RPE would seem appropriate, e.g., melanotic, albinotic or nonpigmented RPE naevi, grouped or solitary type.

\section{References}

${ }^{1}$ Stedman TL: Stedman's Medical Dictionary. 24th ed. Baltimore. Williams \& Wilkins, 1982: 274,619,951,1064.

${ }^{2}$ Gass JDM: Stereoscopic Atlas of Macular Diseases: Diagnosis and Treatment. 3rd ed. St
Louis. CV Mosby Co, 1987: 606-24.

${ }^{3}$ Cardell BS and Starbuck MJ: Juxtapapillary hamartoma of retina. Br J Ophthalmol 1961, 45: $672-7$.

${ }^{4}$ Machemer R: Die Primare retinale Pigmentepithelhyperplasie. Albrecht von Graefes Arch Ophthalmol 1964, 167: 284-95.

${ }^{5}$ Gass JDM: An unusual hamartoma of the pigment epithelium and retina simulating choroidal melanoma and retinoblastoma. Trans Am Ophthalmol Soc 1973, 71: 171-85.

${ }^{6}$ Gass JDM: Differential diasgnosis of intraocular tumours: a stereoscopic presentation. St Louis. CV Mosby Co, 1974: 221-246.

7 Yannuzzi LA, Gitter KA, Schatz H: The macula: A Comprehensive Text and Atlas. Baltimore. Williams \& Wilkins, 1979: 298.

${ }^{8}$ Schachat AP, Shields JA, Fine SL, et al.: Combined hamartomas of the retina and retinal pigment epithelium. Ophthalmology 1984, 91: 1609-14.

${ }^{9}$ Kahn D, Goldberg MF, Jednock N: Combined retinal-retina pigment epithelial hamartoma presenting as a vitreous haemorrhage. Retina 1984, 4: 40-3.

10 Theobald GD,Floyd G, Kirk HQ: Hyperplasia of the retinal pigment epithelium simulating a neoplasm: report of two cases. Am J Ophthalmol 1958, 45: 235-40.

${ }^{11}$ Vogel MH, Zimmerman LE, Gass JDM: Proliferation of the juxtapapillary retinal pigment epithelium simulating malignant melanoma. Doc Ophthalmol 1969, 24: 461-743.

${ }^{12}$ McLean EB: Hamartoma of the retinal pigment epithelium. Am J Ophthalmol 1976, 82: 22732.

${ }^{13}$ Flood TP, Orth DH, Aaberg TM, Marcus DF: Macular hamartomas of the retinal pigment epithelium and retina. Retina 1983, 3: 164-70.

${ }^{14}$ Laqua $\mathrm{H}$ and Wessing $\mathrm{A}$ : Congenital retino-pigment epithelial malformation, previously described as hamartoma. Am J Ophthalmol 1979, 87: 34-42.

${ }^{15}$ Kurz GH and Zimmerman LE: Vagaries of the retinal pigment epithelium. Int Ophthalmol 1962, 2(2): 441-64.

${ }^{16}$ Purcell JJ Jr and Shields JA: Hypertrophy with hyperpigmentation of the retinal pigment epithelium. Arch Ophthalmol 1975, 93: 112226.

${ }^{17}$ Buettner H: Congenital hypertrophy of the retinal pigment epithelium. Am J Ophthalmol 1975, 79: 177-89.

${ }^{18}$ Norris JL and Cleasby GW: An unusual case of congenital hypertrophy of the retinal pigment epithelium. Arch Ophthalmol 1976, 94: 191011. 
${ }^{19}$ Boldry LE and Schwartz A: Enlargement of congenital hypertrophy of the retinal pigment epithelium. Am J Ophthalmol 1982, 94! 64-6.

${ }^{20}$ Blair NP and Trempe CL: Hypertrophy of the retinal pigment epithelium associated with Gardner's syndrome. Am J Ophthalmol 1980, 90: 661-67.

${ }^{21}$ Lewis RA, Crowder WE, Eierman LA, Nussbaum RL, Ferrell RE: The Gardner Syndrome. Significance of ocular features. Ophthalmology 1984, 91: 916-25.

${ }^{22}$ Buetter H: Kongenitale Hypertrophie des Pigmentepithels der Netzhaut und Gardner Syndrom. Fortschr Ophthalmol 1986, 83: 597-99.

${ }^{23}$ Cleary PE, Gregor Z, Bird AC: Retinal vascular changes in congenital hypertrophy of the retinal pigment epithelium. $\mathrm{Br} J$ Ophthalmol 1976, 60: 499-503.

${ }^{24}$ Wirz K, Lee WR, Coaker T: Progressive changes in congenital hypertrophy of the retinal pigment epithelium. Graefe's Arch Clin Exp Ophthalmol 1982, 219: 214-21.

${ }^{25}$ Duke JR and Maumenee AE: An unusual tumour of the retinal pigment epithelium in an eye with early open-angle glaucoma. Am J Ophthalmol 1959, 47: 311-17.

${ }^{26}$ Hoeg N: Die gruppierte Pigmentation des Augengrundes. Klin Monatsbl Augenheilkd 1911, 49: 49-77.

${ }^{27}$ Mauthner L: Lehrbuch der Opthalmoscopie. Vienna. Tendler, 1868: 388.

${ }_{28}^{28}$ Parsons JH: Some anomalies of pigmentation. In Dixieme Congres International d'Ophthalmologie. Lausanne, G Gridel, 1905: 152.

${ }^{29}$ Shields JA and Tso MOM: Congenital grouped pigmentation of the retina: histopathologic description and report of a case. Arch Ophthalmol 1975, 93: 1153-5.

${ }^{30}$ Collier M: Les manifestations oculaires associees a la dyschondroplaise d'Ollier (a propos d'un cas comportant une pigmentation congenitale de la retine.) Bull Soc Ophthalmol Fr, no 4, 1961: 161-69.

${ }^{31}$ Schwarz GT: Case report of congenital grouped pigmentation of the retina with maculocerebral degeneration. Am J Ophthalmol 1943, 26: $72-4$.

${ }^{32}$ McGregor IS: Macular coloboma with bilateral grouped pigmentation of the retina. $\mathrm{Br} J$ Ophthalmol 1945, 29: 132-6.

33 Gasparova D and Szedelyova L: Familial occurence of grouped pigmentations in ocular fundus. Cesk Oftalmol 1980, 36: 406-8.

${ }^{4}$ Schlernitzauer DA and Green WR: peripheral retinal albinotic spots. Am J Ophthalmol 1971, 72: 729-32.

${ }^{35}$ Green WR: In Spencer WH ed. Ophthalmic pathology, an atlas and textbook. 3rd ed, Vol 2. Philadelphia: WB Saunders 1985: 1227-35.

36 Jampol HD, Schachat AP, Conway B, Shaver $\mathrm{RP}$, et al.: Retinal pigment epithelial hyperplasia assuming tumour-like proportions. Report of two cases. Retina 1986, 6: 105-112.

${ }^{37}$ Blodi FC, Rueling FH, Sornson ET: Pseudomelanocytoma at the optic nervehead: An adenoma of the retinal pigment epithelium. Arch Ophthalmol 1965, 73: 353-5.

${ }^{38}$ Font RL, Zimmerman LE, Fine BS: Adenoma of the retinal pigment epithelium. Histochemical and electron microscopic observations. Am J Ophthalmol 1972, 73: 544-54.

${ }^{39} \mathrm{Greer} \mathrm{CH}$ : Epithelial tumours of the retinal pigment epithelium. Trans Ophthalmol Soc UK 1952, 72: 265-77.

${ }^{40}$ Garner A: Tumours of the retinal pigment epithelium. Br J Ophthalmol 1970, 54: 71523.

${ }^{41}$ Tso MOM and Albert DM: Pathological conditions of the retinal pigment epithelium. Arch Ophthalmol 1972, 88: 27-38.

${ }^{42}$ Rosenberg PR and Walsh JB: Retinal pigment epithelial hamartoma--unusual manifestations. Br J Ophthalmol 1984, 68: 439-42.

${ }^{43}$ Corcostegui B, Mendez M, Corcostegui et JJ, Gibernau G: Elements diagnostiques des hamartomes de la reina et de l'epithelium pigmentaire. Bull et Mem SFO 1985, 96: 152-59.

${ }^{44}$ Cosgrove JM, Sharp DM, Bird AC: Combined hamartoma of the retina and retinal pigment epithelium. Trans Ophthalmol Soc UK 1986, 105: 106-13.

${ }^{45}$ Cotlier E: Cafe-au-lait spots of the fundus in neurofibromatosis. Arch Ophthalmol 1977, 95: $1990-2$.

${ }^{46}$ Hrisomalos N, Mansour AM, Jampol LE, Fowell SM, Greenwald MJ: 'Psuedo'-combined hamartoma following papilledema. Arch Ophthalmol 1987, 105: 1634-5.

${ }^{47}$ McDonald HR, Abrams GW, Bruke JM, Neuwirth J: Clinicopathologic results of vitreous surgery for epiretinal membranes in patients with combined retinal and retinal pigment epithelial hamartomas. Am J Ophthalmol 1985, 100: 806-13.

${ }^{48}$ Parke JT, Riccardi VM, Lewis RA, Ferrell RE: A syndrome of microcephaly and retinal pigmentary abnormalities without mental retardation in a family with coincidental autosomal dominant hyperreflexia. Am J Med Genet 1984, 17: 585-94.

${ }^{49}$ Kandori F: Very rare case of congenital nonprogressive night blindness with fleck retina. Jpn J Clin Ophthalmol 1959, 13: 384. 
${ }^{50}$ Kandori F, Setogawa T, Tamai A: Electroretinographical studies on 'fleck retina with congenital nonprogressive night blindness.' Yenago Acta Med 1966, 10: 98.
${ }^{51}$ Kandori F, Tamai A, Kurimoto S, Fukunaga K: Fleck retina. Am J Ophthalmol 1972, 73: 67385 . 